\title{
Effect of Pimpinella anisum $L$ (Aniseed) Aqueous Extract against Lead (Pb) Neurotoxicity: Neurobehavioral Study
}

\author{
Amina Bekara ${ }^{1, *}$, Nadia Ait Hamadouche ${ }^{1}$, Khaled Kahloula ${ }^{2}$, Sara Harouat ${ }^{1}$, Dalila Tabbas ${ }^{1}$, \\ Abd-el-Kader Aoues ${ }^{1}$ \\ ${ }^{1}$ Laboratory of Experimental Bio-toxicology, Bio-depollution and Phyto-remediation, Department of Biology, University of Oran 1 \\ (Ahmed Benbella), Algeria \\ ${ }^{2}$ Laboratory of Biochemistry, Department of Biology, University of Saida, Algeria
}

Copyright (C) 2015 by authors, all rights reserved. Authors agree that this article remains permanently open access under the terms of the Creative Commons Attribution License 4.0 International License

\begin{abstract}
Pregnant rats received 0, 2\% of lead acetate $(\mathrm{Pb})$ in drinking water. The treatment with the aqueous extract of Pimpinella anisum L (P.A.E.) started after weaning with dose of $750 \mathrm{mg} / \mathrm{kg}$ and for 15 successive days . The effect of the extract was evaluated through behavioral tests : open filed (OF), Forced swimming test ( FST) and dark /light test . Beside; Lactate dehydrogenase (LDH), total plasmatic proteins, alkaline phosphatase (ALP), lipid peroxidation (TBARS) and Catalase (CAT) were analyzed. Lead induced a hyperactivity in the open field which was reduced after administration of P.A.E. In the FST, the treatment with plant extract enhanced significantly the mobility time compared with intoxicated group. We had observed that time spent in the dark compartments in dark and light test was reduced after oral administration of P.A.E. Lead caused significant increase in LDH, TBARS and ALP, in contrary this toxic agent decrease the levels of plasmatic proteins and catalase activity in cerebellum and cerebrum . We can conclude that oral treatment with aniseed aqueous extract was effective in reducing the level of some of biochemical parameters and ameliorate behavior of intoxicated rats by lead.
\end{abstract}

Keywords P.anisum L, Aqueous Extract, Lead Acetate, Neurobehavioral Tests, Cerebellum and Cerebrum

\section{Introduction}

For many ages, herbs formed the main source of therapeutics that have been used to help in relief from illness, hence herbal treatment is still used but a small percentage of living plant have been phytochemically investigated[1]. Plants extracts are considered nowadays as a potential source for bioactive molecules that can affect positively or negatively on different cellular processes [2].

Pimpinella anisum L (Family: Apiaceae) is an annual herb indigenous to near East and widely cultivated in the Mediterranean. The principal constituents of the fruit are volatile oil, fatty acids, coumarins, flavonoids, glycosides, proteins and carbohydrates [3]. The seeds as well as essential oil have been used as anti-oxidants, antispasmodic, anti-microbial, digestive stimulant, galactogogue [4]. Whereas few studies have investigated the effect of this plant on neurological disorders, however, in Iranian folk medicine, the traditional healers described aniseed as a treatment for epilepsy and convulsion [5].

Lead is the most common neurotoxin agent that is widely distributed in the environment; many studies suggested that the neurotoxin effect of this non-essential element are mediated by interference directly or non-directly with cholinergic and aminergic system [6]. Exposure to this heavy metal in earlier life has been showed to produce impairment in the processes of learning, memorization and motor coordination.

In the presence of all this huge data which confirmed the hazardous effect of lead on nervous system especially in children, this study was conducted to investigate the possible beneficial effect of an oral administration of $P$. anisum $\mathrm{L}$ aqueous extract on lead induced neuro-behavioral damage in young rats .

\section{Material and Methods}

\subsection{Plant Material}

The dry and ripe seeds of Pimpinella anisum $L$ were purchased from a local herbs market in Chlef Center (Algeria) and were identified by an expert taxonomist. A voucher specimen was deposited in the herbarium of department of Biology, Faculty of Science, Oran University (Algeria).

\subsubsection{Aqueous Extract Preparation}

The seeds of Pimpinella anisum $L$ were grounded; $100 \mathrm{~g}$ of 
the powder were immerged in $1 \mathrm{~L}$ of distilled water on heat for 15 minutes [7]. The aqueous extract was filtered through Wathman paper $\mathrm{N}^{\circ} 1$, and the filtrate was after that lyophilized (CHRISI, ALPHA 1-2LD, Germany). The yield of extraction was $20,99 \%$.

\subsection{Animals}

Females Wistar rats (Rattus norvegicus) weighting $200 \pm$ $30 \mathrm{~g}$ were used in this study. All animals were obtained from Department of Biology, Faculty of Science, University Of Oran 1 . The animals were housed in standards conditions with free access to food and water $\left(12 \mathrm{~h}\right.$ light/dark, $\mathrm{T}^{\circ}$ $22 \pm 2^{\circ} \mathrm{C}$ ). All the procedure performed on animals were approved and conducted in accordance with the National Institute of health Guide (Reg. No. 488/160/1999/CPCSEA).

After one week of cohabitation with males, females were divided into 02 groups [8]:

Group 1: Pregnant females received drinking water without lead acetate $(\mathrm{Pb})$.

Group 2: Pregnant females received $0,2 \%$ of lead acetate $(\mathrm{Pb})$ in drinking water.

\subsubsection{Experimental Design}

At birth, pups issued from intoxicated females, continued to receive lead acetate in drinking water until weaning, while control pups received only distilled water. At weaning, we got 03 new groups $(n=8)$ as follow:

Group C: Control rats (issued from control females) received distilled water.

Group Pb: intoxicated rats with lead (issued from intoxicated females) that received distilled water orally as vehicle solution.

Group Pb + P.A.E: intoxicated rats (issued from intoxicated females) that received orally P.anisum aqueous extract (P.A.E) at dose of $750 \mathrm{mg} / \mathrm{Kg}$ daily for Two weeks [3].

\section{Neurobehavioral Study}

\section{Open Field Test (OF)}

This test evaluated the general motor activity of rats. The apparatus was constructed of poly- wood and measured $72 \times$ $72 \mathrm{~cm}$ with 36 walls. The lines divided the floor into sixteen $18 \times 18 \mathrm{~cm}$ squares. Each animal was placed in the center of the arena and allowed to explore the apparatus for 5 minutes. The following parameters were recorded through the test: Number of squares crossing, Center squares entries, Rearing (Frequency with which the animal stood on their hind legs) Grooming and Defecation (Number of boli produced).

\section{Forced Swimming Test (FST)}

The rat was placed in glass cylinder $(39 \mathrm{~cm}$ height $\times 20 \mathrm{~cm}$ diameter) containing water at $22{ }^{\circ} \mathrm{C}$ and $30 \mathrm{~cm}$ of deep. Tow swimming session were conducted: an initial 10 minutes pre-test followed 24 hours by six minutes test. After swimming session, each rat was removed from the cylinder, dried and returned to their home cage. The parameters recorded during the test were time of mobility and immobility time.

\section{Dark and Light Test (DLT)}

In this test, we allowed animal to discover the arena formed by two compartments: one with light and the other dark. Rat's generally hated places with light, hence more the animals is no anxious, more its exploration would be reduced in the dark compartment. The parameters recorded in this test are time spent in the dark compartment and time spent in the light compartment.

\section{Sacrifice}

At the end of the behavioral tests, rats were killed in the morning after 12 hours of fasting. Sacrifice was done by cervical decapitation after injection in I.P of anesthesia (Chloral solution $3 \mathrm{ml} / \mathrm{Kg}$ ). The brain was removed, rinsed with physiological solution $(\mathrm{NaCl} 0,9 \%)$ and stored at $-80{ }^{\circ} \mathrm{C}$ until use. Blood was collected in heparin tubes, and then it was centrifuged $3000 \mathrm{rpm} / 10$ minutes. Samples of plasma were conserved for further Biochemical [9].

\subsection{Biochemical Analyses}

The dosage of Lactate Dehydrogenase (LDH) and total plasmatic proteins was made on the recuperated plasma by using commercial kits (CHRONOLAB).

\subsubsection{Preparation of Brain Homogenates}

Cerebrum and Cerebellum were separated and cleaned with ice-cold saline solution. Brain parts were homogenized in a proportion of 1:10 (W/V) ice-cold KCL buffer $(1,15 \%$; $\mathrm{pH} 7,2)$. The homogenate was centrifuged at $10.000 \times \mathrm{g}$ for 10 minutes at $4^{\circ} \mathrm{C}$ to obtained post -mitochondrial supernatant (PMS) which was used for the quantification of ALP , Lipid peroxidation and Catalase.

\subsubsection{Dosage of Alkaline Phosphatase (ALP)}

The assessment of alkaline phosphatase (ALP) in the brain was measured by using commercial kits (CHRONOLAB).

\subsubsection{Lipid Peroxidation (TBARS)}

The level of lipid peroxidation was determined as described by [10]. Briefly, to $0,2 \mathrm{ml}$ of brain homogenate, we add in the following order : $0,2 \mathrm{ml}$ of Sodium lauryl phosphate $(8,1 \%), 1,5 \mathrm{ml}$ of acid acetic $(20 \%, \mathrm{pH} 3,5)$ and $1,5 \mathrm{ml}$ of aqueous solution of Thiobarbituric acid $(0,8 \%)$. The volume of the solution was made up to $4 \mathrm{ml}$ by adding distilled water and heated at $95{ }^{\circ} \mathrm{C}$ for 60 minutes. After cooling in ice bath, $4 \mathrm{ml}$ of n-Butanol and $1 \mathrm{ml}$ of distilled water were added to the mixture and centrifuged. The organic layer separated and its absorbance was measured at $532 \mathrm{~nm}$. The result was expressed as $\mu \mathrm{mol}$ of MDA/ mg of proteins tissue. 


\subsubsection{Catalase Activity (CAT)}

The catalase activity was measured following the methods of [11]. Briefly, $50 \mu \mathrm{l}$ of homogenate and $750 \mu \mathrm{l}$ of phosphate buffer $(0,1 \mathrm{M}$; pH 7,5$)$ were incubated into tube, hence after adding $200 \mu \mathrm{l}$ of $\mathrm{H}_{2} \mathrm{O}_{2}(50 \mathrm{mM})$, the chronometer was set on. After one minute, the reaction was stopped by adding $2 \mathrm{ml}$ of Potassium Dichromate solution (5\%). Each tube was heated at $100{ }^{\circ} \mathrm{C}$ for 10 minutes. After cooling, the absorbance of the samples was measured at $570 \mathrm{~nm}$. The catalase activity was expressed as $\mathrm{mM}$ of $\mathrm{H}_{2} \mathrm{O}_{2}$ degraded / $\mathrm{min} / \mathrm{mg}$ of proteins.

\subsection{Statistical Analysis}

All results were expressed as mean \pm S.E.M (Standard of Error). The data analysis was carried out by using statistical software: R. Kruskal Wallis rank test (a non-parametric test) was used to examine the difference between independent groups and the Wilcoxon rank sum test (a non-parametric test) was used to examine the difference between the dependent groups using $\mathrm{R}$ software. Value of $\mathrm{p}<0,01$ and $\mathrm{p}$ $<0,05$ were taken as the significant level.

\section{Results}

\section{Body and Brain Weight}

The weight was evaluated for 15 successive days, the results in table (1) showed that lead increased the body weight (B.W), in contrary we observed that the control group represented the lower body weight, however in the treated group with P.A.E we noted a significant increase in the B.W compared $(p<0,01)$ to other groups. Concerning the brain weight (table 1), the results showed that lead induced a decrease in the brain weight of exposed rats when compared to the controls $(p<0,01)$, whereas in the treated group with P.A.E, we had observed a significant increase $(\mathrm{p}<0,01)$ compared to intoxicated group.

\section{Open Field Test}

The open field experiment demonstrated that exposure to lead $(\mathrm{Pb})$ during pregnancy and lactation increased the number of crossed squares $(p<0,05)$ and reduced the grooming $(\mathrm{p}<0,01)$ compared to control group (Table 2 ). Hence, the oral administration of P.A.E. showed a significant reduction in some parameters of the open field test like Number of visit in central squares $(p<0,05)$ and defecation $(\mathrm{p}<0,01)$, whereas for the other parameters no significant changes was recorded.

Table 1. Effect of $\mathrm{Pb}$ and P.A.E on body and brain weight of tested rats.

\begin{tabular}{|c|c|c|}
\hline & Body weight (g) & Brain weight (g) \\
\hline Group C & $32,16 \pm 1,68$ & $1,61 \pm 0,054$ \\
\hline Group Pb & $37,74 \pm 4,80^{* *}$ & $1,40 \pm 0,099^{* *}$ \\
\hline Group Pb+ P.A.E. & $61,19 \pm 2,60^{* *}$ & $1,57 \pm 0,072^{*}$ \\
\hline
\end{tabular}

$(* *) \mathrm{p}<0,01$

Table 2. Effect of lead $(\mathrm{Pb})$ and oral administration of P.A.E on Open Filed parameters.

\begin{tabular}{|c|c|c|c|c|c|}
\hline & $\begin{array}{c}\text { Number of crossed } \\
\text { squares }\end{array}$ & $\begin{array}{c}\text { Number of visits in } \\
\text { central square }\end{array}$ & Rearing & Grooming & Defecation \\
\hline Group C & $128,2 \pm 29,20$ & $7,8 \pm 2,57$ & $55 \pm 15,61$ & $12,4 \pm 1,46$ & $1 \pm 0,02$ \\
\hline Group Pb & $158 \pm 14,13^{*}$ & $28,8 \pm 12,2 *$ & $68 \pm 11,71$ & $5,8 \pm 1,23^{* *}$ & $2,66 \pm 0,40^{*}$ \\
\hline Group Pb+ P.A.E. & $141,6 \pm 27,48$ & $24,4 \pm 5,55^{*}$ & $88 \pm 19,01$ & $19,8 \pm 2,98^{* *}$ & $1,30 \pm 0,58^{* *}$ \\
\hline
\end{tabular}

$(*) \mathrm{p}<0,05 ;(* *) \mathrm{p}<0,01$. 


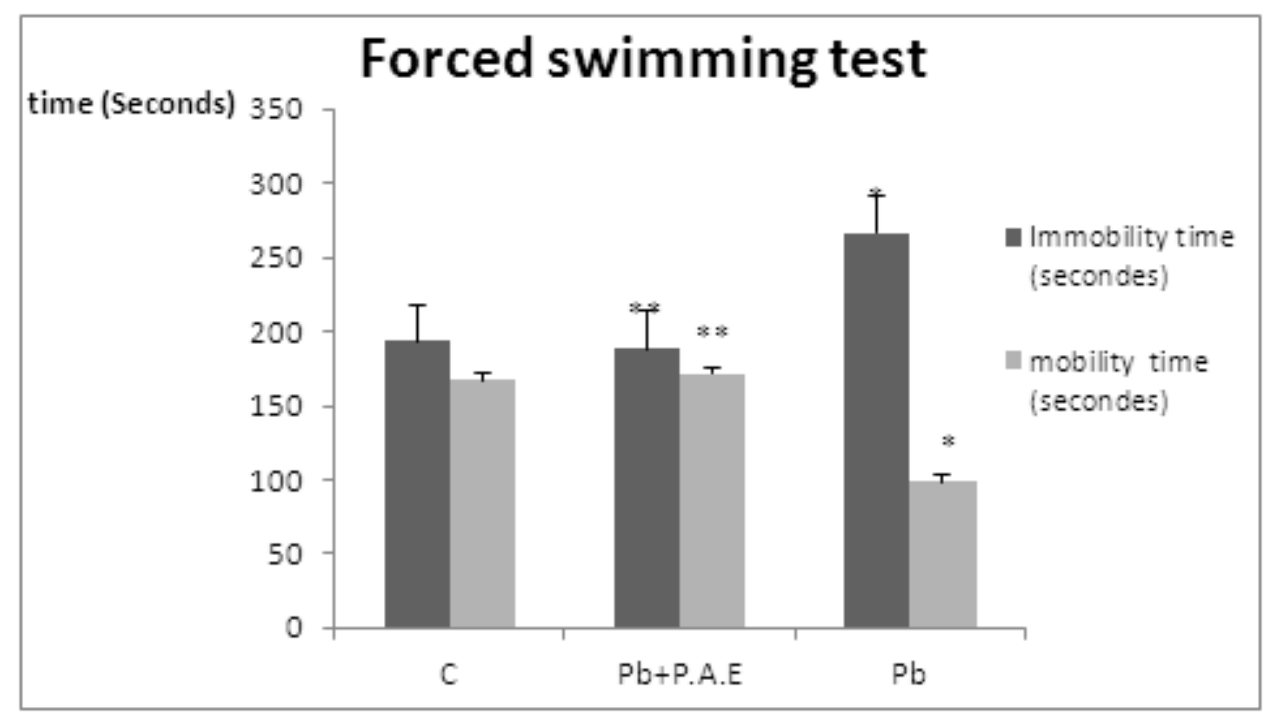

Figure 1. Results of forced swimming test obtained after 6 minutes of experimentation: Control group, $\mathrm{Pb}$ : intoxicated group, $\mathrm{Pb}+\mathrm{P} . \mathrm{A}$.E: intoxicated and treated group with P.anisum aqueous extract.

\section{Forced Swimming Test}

The results of this test showed a significant increase of immobility time in the exposed animals to lead $(\mathrm{Pb})$ when compared to control group $(p<0,05)$ (Figure 1). Likewise, we noted a significant $(p<0,01)$ reduction of the immobility time in the treated group with P.A.E comparatively to other groups.

\section{Dark and Light Test}

Lead $(\mathrm{Pb})$ ingested by mother rats during gestation and lactation caused a decrease of time spent in the dark compartment of exposed rats when compared to controls rats $(p<0,05)$. Thus, oral treatment with aniseed aqueous extract increased significantly the time spent in the dark compartment comparatively with other groups $(\mathrm{p}<0,05)$, figure (2).

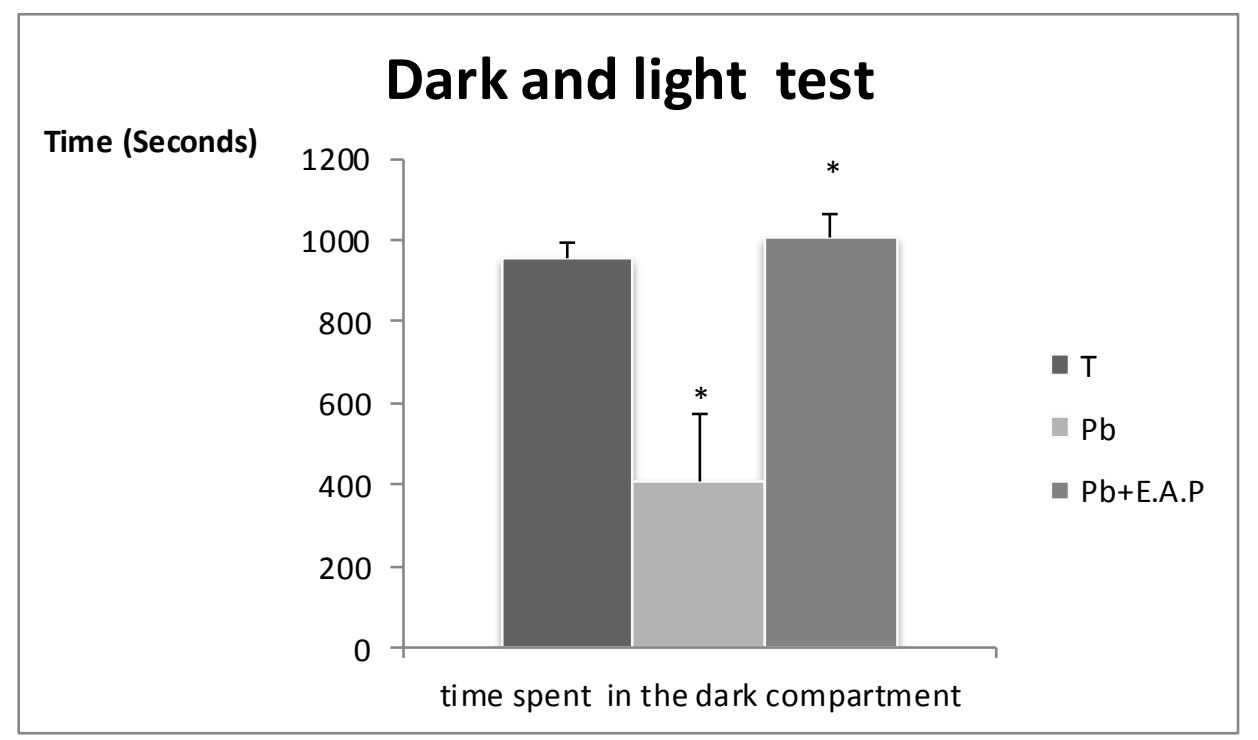

Figure 2. Results of dark and light test. $\mathrm{C}$ : Control group, $\mathrm{Pb}$ : intoxicated group, $\mathrm{Pb}+\mathrm{P}$.A.E: intoxicated and treated group with $\mathrm{P}$.anisum aqueous extract.

\section{LDH and Total Proteins}

Exposure to lead induced a significant increase in the LDH levels $(1348 \pm 317 \mathrm{U} / \mathrm{L})$ in intoxicated Group compared to the control $(801,95 \pm 261 \mathrm{U} / \mathrm{L})$ with $\mathrm{p}<0,01$. In treated group with P.A.E., no significant reduction of LDH level was observed, in contrary a little augmentation in the concentration of this enzyme was registered $(1500,27 \pm 391 \mathrm{U} / \mathrm{L})$ when compared to the intoxicated group. (Table 3).

As showed in table (03), lead induced a significant decrease in total plasmatic proteins compared to the control group. Whereas, after oral treatment with aniseed aqueous no significant increase in the proteins levels of $\mathrm{Pb}+\mathrm{P}$.A.E group was observed. 
Table 3. Effect of $\mathrm{Pb}$ and P.A.E. On $\mathrm{LDH}$ and Total proteins levels of tested rats.

\begin{tabular}{|c|c|c|}
\hline & LDH ( U/L) & Proteins (g/d) \\
\hline Group C & $801,95 \pm 95$ & $71,32 \pm 3,90$ \\
\hline Group Pb & $1348,21 \pm 21^{* *}$ & $58,24 \pm 7,21^{*}$ \\
\hline Group Pb+ P.A.E & $1500,27 \pm 391$ & $43,12 \pm 4,13$ \\
\hline
\end{tabular}

(*) $\mathrm{p}<0,05(* *) \mathrm{p}<0,01$

Table 4. Effect of lead $(\mathrm{Pb})$ and oral administration of $\mathrm{P}$.anisum L extract on ALP, Lipid peroxidation and catalase activity of the three tested groups.

\begin{tabular}{|c|c|c|c|c|c|c|}
\hline & \multicolumn{2}{|c|}{ Level of ALP (U/L) } & \multicolumn{2}{|c|}{$\begin{array}{l}\text { Lipid peroxidation ( } \mu \mathrm{M} \text { of MDA} / \mathrm{Mg} \\
\text { of proteins tissue }\end{array}$} & \multicolumn{2}{|c|}{$\begin{array}{c}\text { Catalase }\left(\mathrm{mM} \mathrm{H}_{2} \mathrm{O}_{2} / \mathrm{min} / \mathrm{mg} \text { of }\right. \\
\text { proteins }\end{array}$} \\
\hline & Cerebrum & Cerebellum & Cerebrum & Cerebellum & Cerebrum & Cerebellum \\
\hline Group C & $46,29 \pm 14,88$ & $23,71 \pm 5,94$ & $14,65 \pm 0,69$ & $10,97 \pm 1,36$ & $2,82 \pm 0,31$ & $3,27 \pm 0,41$ \\
\hline Group Pb & $58,5 \pm 22,06^{*}$ & $27,54 \pm 4,75^{*}$ & $16,60 \pm 1,09^{*}$ & $17,71 \pm 2,71 * *$ & $1,75 \pm 0,52 *$ & $1,68 \pm 0,05^{*}$ \\
\hline $\begin{array}{l}\text { Group Pb+ } \\
\text { P.A.E }\end{array}$ & $57,12 \pm 18,63$ & $22,79 \pm 6,99$ & $15,33 \pm 1,11^{*}$ & $8,00 \pm 1,37 * *$ & $2,82 \pm 0,53$ & $3,27 \pm 0,41$ \\
\hline
\end{tabular}

(*) $\mathrm{p}<0,05(* *) \mathrm{p}<0,01$

\section{Alkaline Phosphatase (ALP), Lipid Peroxidation and Catalase Activity}

The results of the study (Table 4) showed that lead intoxication caused a significant increase in the ALP Level from 46,29 $\pm 14,88 \mathrm{U} / \mathrm{L}$ (Control group) to $58,5 \pm 22,06 \mathrm{U} / \mathrm{L}$ ( $\mathrm{Pb}$ group) in Cerebrum and from 23,71 $\pm 5,94 \mathrm{U} / \mathrm{L}$ (Control group) to $27,54 \pm 4,75 \mathrm{U} / \mathrm{L}$ ( $\mathrm{Pb}$ group) in Cerebellum. However, we had observed a non-significant decrease in ALP level after treatment with aniseed aqueous extract in both cerebrum and cerebellum respectively as compared to intoxicated group : 57,12 $\pm 18,63 \mathrm{U} / \mathrm{L}$ (Cerebrum ) and 22,79 $\pm 6,99 \mathrm{U} / \mathrm{L}$ (Cerebellum)

MDA is a marker of lipid peroxidation, the results showed (Table 4) that the level of MDA in intoxicated group was (16, $06 \pm 1,0 \mu \mathrm{M})$ compared to control group $(14,65 \pm 0,65 \mu \mathrm{M})$ in Cerebrum. Hence, in Cerebellum, the rate of MDA increased from 10,79 $\pm 1,36 \mu \mathrm{M}$ for Control group to $17,7 \pm 2$, $71 \mu \mathrm{M}$ for intoxicated group. A significant reduction of lipid peroxidation levels was observed after treatment with Pimpinella anisum aqueous extract $(15,33 \pm 1,11 \mu \mathrm{M}$ in Cerebrum and 8, $00 \pm 1,37 \mu \mathrm{M}$ in Cerebellum) comparatively to intoxicated group $(\mathrm{p}<0,01)$.

For the catalase activity (Table 4), we can observed that lead poisoning induced depletion in the enzyme activity from $2,82 \pm 0,31 \mathrm{mM} \mathrm{H}_{2} \mathrm{O}_{2}$ (control rats ) to $1,75 \pm 0,52 \mathrm{mM} \mathrm{H}_{2} \mathrm{O}_{2}$ ( $\mathrm{Pb}$ group) in Cerebrum, and from 3,27 $\pm 0,41 \mathrm{mM} \mathrm{H}_{2} \mathrm{O}_{2}$ to $1,68 \pm 0,05 \mathrm{H}_{2} \mathrm{O}_{2}$ in cerebellum as compared to control group respectively $(p<0,05)$. Hence, Non-Significant elevation of catalase was observed after treatment of rats with P.A.E as compared to intoxicated group $(\mathrm{Pb})$, therefore the plant extract increase the level of catalase as : $2,82 \pm 0,53 \mathrm{mM}$ $\mathrm{H}_{2} \mathrm{O}_{2}$ in cerebrum and $3,27 \pm 0,03 \mathrm{mM} \mathrm{H}_{2} \mathrm{O}_{2}$ in Cerebellum respectively $(\mathrm{p}<0,05)$.

\section{Discussion}

The primary site of action of lead is nervous system [12]. This heavy metal has shown demonstrable neurological effects [13] and behavioral disorders [14] including deficits in learning, spatial memory and motor skills. Previous data suggested that the neurotoxic effects of lead are mediated through interference with cholinergic and aminergic system [6]. Hence, oxidative stress has been also proposed to be another mechanism involved in the $\mathrm{Pb}$ toxicity. Moreover, earlier exposure to lead through placenta and lactation is more dangerous because Blood-Brain -Barrier (BBB) is still immature and it is highly permeable during the first phase of brain development. In fact, several studies have demonstrated that neuronal development start from fetal stage and continue until adolescence [15].

\section{Body and Brain Weights}

Our results showed that lead exposure during gestation and lactation caused an increase in the body weight of the pups but many others studies have demonstrated that lead caused a decrease in the body weights [8], [16].In contrary to this data and in accordance with our finding, two studies have previously reported higher body weight in offspring developmentally exposed to low level of lead [17], [18]. Refereeing to [18] and its team have proposed a possible compensatory response to high toxic insult, refereeing to [17] suggested a number of mechanisms, such as lead $(\mathrm{Pb})$ induced polymorphisms in Vitamin D receptors, interference with endocrine signaling pathways and altered hypothalamic - pituitary -adrenal axis(HPA) to explain high weight gain . In agreement to this data [19] have studied the effect of low level chronic exposure to lead on physical development of Children in Boston and concluded that early $\mathrm{Pb}$ exposure can lead to obesity that persist in adulthood. Besides, lead caused a significant decrease in the weight of Cerebrum and Cerebellum; this effect could result of high vulnerability of cerebral cortex towards various toxic.

Treatment with Pimpinella anisum $\mathrm{L}$ aqueous extract (P.A.E) at $750 \mathrm{mg} / \mathrm{kg}$ for 15 days increased significantly the body weight. This effect may be attributed to the bio-actives compounds of aniseed such as Anethole, Eugenol, Anisaldehyde, Estragol and Methylchavicol, which have a 
particular stimulant effect on digestive system, cause Anethole the main compound in Pimpinella anisum $L$ affected pathogen micro-organism in the digestive system and showed increasing effect on weight gain and feed conversion. It was reported that anise oil affected positively the digestibility of nutrient [20]. Indeed ; aniseed is rich in nutritive compounds which can have a positive effect on body weight gain like : proteins $18 \%$, Fatty oil $8-23 \%$, essential oil $2-7 \%$, sugars $3-5 \%$ and crude fiber $12-15 \%[21]$.

\section{Open Field (OF)}

The current finding showed that exposure to lead during gestation and lactation affected the locomotor activity in the Open Filed test. Further, lead caused a significant hyperactivity, which was in accordance with lot of studies [8], [22]. Many suggestions have been proposed to explain this effect, some of this relied the change in the open field behavior to the alteration of dopaminergic, serotonergic and cholinergic systems [14]. Hence, lead caused a direct inhibition of acetylcholine during brain development. Moreover, alterations caused by this toxic element on different neurotransmitters in prefrontal cortex are involved in the hyperactivity recorded during open field test .The cholinergic system is responsible for neurobehavioral manifestations during lead poisoning which result most often by a locomotive and cognitive dysfunctions in animals. This effect was clearly reflected by the hyperactivity recorded in the open Field test.

In another hand, lead caused anxiety, which was translated by the high number of visits in central squares; this can be considered as a good measurement for anxiety behavior cause rodents seems to prefer the corners and avoids the center of the apparatus. In addition, the high number of rearing recorded in this test was considered also as indicator for anxiety [25]. Lead caused an anxiety like behavior, this effect may have a link with the hippocampal serotonin and dopamine neurons. These systems are involved in the regulation of Corticotropin releasing factor (CRF) which plays an important role on the system implicated in the anxiety like behavior .

The hyper- locomotor activity observed in intoxicated rats was less in the treated group by P.anisum aqueous extract, this effect may be due to the activation of GABA receptors [26]. It has been shown that aniseed oil exerts its effects on opioid receptors via activation of GABA receptors in mice. In addition, it has been revealed that aniseed oil can enhance the activity of $\mathrm{Na}+-\mathrm{K}+\mathrm{ATP}$ ase [5], [2]. $\mathrm{Na}+-\mathrm{K}+$ pumps play an important role in the regulation of neuronal excitability.

\section{Forced Swimming Test (FST) and Dark /Light Test (DLT)}

In FST, immobility time was higher in exposed rats to lead during gestation and lactation, which reflect a depression state. This effect is due mainly to the direct action of lead on serotoninergic and glutamatergic transmission in brain and its receptors respectively: 5HT1A and NMDA which are involved in the physiopathology of depression [27], [28].Anxiety caused by lead acetate was also confirmed through Dark and light test. Hence, our results were in agreement with the finding of [8].However, this effect can be explained by the interaction of lead with serotoninergic and dopaminergic neurons in Hippocampus. This system seems to be involved in the regulation of CRF (Corticotropin Releasing Factor) which play a key role in anxiety behavior. The increase of immobility time in the forced swimming test is due to the fact that Lead acted like a depression element on serotoninergic system in different brain areas , mainly the striatum, hippocampus and hypothalamushypophysaire axis .

Aniseed contain 1, 5 -6\% of volatile oil which is composed mainly of Trans -Anethole (88 \%) [29] Which is largely used as substrate for the synthesis of various substances of neuro- pharmaceutical interest such as anti-convulsant and sedative drugs [30]. Several studies have demonstrated the potential of aniseed extract and essential oil to act on central nervous system (CNS), it was reported that aqueous extract of this plant delay (but not prevent) the onset of picrotoxin-induced seizures in mice[31]. [32] Suggested that aniseed may act by both increasing seizures threshold and inhibiting it spread. Previous data have shown that P.anisum and especially its essential oil (E.O) exerted a neuro-protective effect, which is probably mediated by the enhancement of NMDA functions. According to [33]; Anise E.O induced neuronal excitability, which was attributed to the activation of $\mathrm{Ca}^{2}+$ canals or to the inhibition of $\mathrm{Ca}^{2+} / \mathrm{K}^{+}$ voltage dependent canal.

\section{Totals Proteins, LDH and ALP}

From this data, we can see that lead exposure during gestation and lactation induced a significant increase in the levels of LDH and ALP, whereas it has decreased the values of totals proteins. Ours results were in accordance with others studies [34], [35] and [36].Lead acetate induced a significant decrease in totals proteins, which was in agreement with the study of [37]. The decrease in serum total proteins was attributed to both hepatic and renal damage induced by this toxic agent, hence this effect may be due also to the binding of lead ions to plasmatic proteins, where its caused alteration in high number of enzymes and can also disturb proteins synthesis in hepatocytes. Moreover, the decreasing in the proteins levels may be explained by the decrease of hepatic DNA and RNA induced by lead intoxication or due to diminution of utilization of free amino acids for proteins synthesis [38]. Pb exposure caused an increase in the LDH levels, which was in agreement with the studies of [37], [22]. This effect may be produced by the damage of red blood cells (RBC) membrane, hence this augmentation may be attributed also to the alterations of redox status, and however accumulation of free radicals can act as stimulant of LDH release.

Alkaline phosphatase play an important role in transmission and development of brain, hence the function of this enzyme are more active in certain part of brain such as 
primary air and frontal [39]. Our results indicated that lead exposure during development induced a significant increase of ALP levels in both cerebrum and cerebellum which was in agreement with others studies[37], [22].The increase in PAL values may be attributed to the damage of Kidney, liver and bone following lead exposure . Moreover, it has been reported that the leakage of ALP activity was associated to the deficit in mineralization [9].

The most probable mechanism for the lead toxicity was through inducing oxidative stress in different cells whereas many studies have reported that Pimpinella anisum exhibited a potential antioxidant activity [40], [4].In fact , several studies have confirmed that $P$.anisum $\mathrm{L}$ possess a significant reducing power which can serve as an indicator of its potential antioxidant propriety. The compounds that are responsible of antioxidant activity in aniseed: Caffiec acid, Camphene, Chlorogenic acid, Rutin and Stigmasterol. Some of them reduce radicals by donating hydrogen atoms [40].

\section{Lipid Peroxidation and Catalase Activity}

The most widely test used for the oxidative stress is the measurement of MDA, a product of lipid peroxidation by the Thiobarbituric Acid Reacting Substance Assay. Ours results showed that lipid peroxidation level was increased in both Cerebrum and Cerebellum after an exposure to lead acetate during gestation and lactation which was in accordance with the study of[41].The high levels of MDA recorded in brain of intoxicated rats may be explained by alteration of lipid membranes attributed to lead which consequently caused an alteration in membranes integrity, permeability and functions[42]; these data correlate with the sensitivity of brain to lead intoxication during development until Blood-Brain -Barrier (BBB) is fully functional[43]. It has been reported that lead is a potential agent for inducing oxidative stress by production of ROS. The concentration of ROS in the organism is controlled by several defense mechanisms, which involved antioxidant and detoxifying enzymes [44]. Therefore, the neurotoxic effect of lead may be due in part to the disruption of pro and anti-oxidant balance. Ours results showed that treatment with P.anisum aqueous extract decreased the level of lipid peroxidation in brain of intoxicated rats, which agree with the finding of [40]. This effect could be attributed to the Phyto-chemicals radicals scavenging present in the plant. Hence, [45] through their study on P.anisum extract confirmed that polyphenols are efficient in preventing lipid peroxidation. Polyphenols represent a group of bioactive compounds that occur in almost plants. Several studies have reported that polyphenols presents in the seeds of P.anisum $L$ donate electron and react with free radical to convert them to more stable products . Thus, allow to make equilibrium again between pro-oxidant/antioxidant balances, which reduced the lipid peroxidation.

Catalase activity was significantly decreased after lead exposure during gestation and lactation, which was in agreement with [46]. This diminution of enzyme levels in both cerebrum and cerebellum can be attributed to the reduction of iron absorption or to the inhibition of Hem biosynthesis. Moreover, the decrease of catalase activity could be the result of decrease in substrate levels [47] or to the reduced synthesis of the enzyme, it's self as a result of high intra - Cellular concentration of lead [22].The oral administration of aniseed aqueous extract enhanced the activity of catalase in both cerebrum and cerebellum. It has been suggested that bio- actives constituents of aniseed are responsible of this effect, because they play a role of radical scavenging by donating hydrogen atoms or by acting as chain breaking agents in lipid peroxidation. According to[4];P.anisum aqueous extract exhibited a potential anti-oxidant activity which was attributed to various mechanisms such as: prevention of chain interaction, binding of transition metal ion catalysts, decomposition of peroxides, prevention of continued hydrogen abstraction , reductive capacity and radicals scavenging [48], [49]. Moreover, this activity is attributed to the presence of some bioactive compounds such as : Caffiec acid, Camphene, Chlorogenic acid , Rutin and Stigmasterol which reduced radicals (like $\mathrm{H}_{2} \mathrm{O}_{2}$ ) by donating hydrogen atom thus leading to the improvement of catalase activity exhausted after exposure to lead acetate.

\section{Conclusions}

From this data, we can conclude that P.anisum $\mathrm{L}$ aqueous extract may have a possible beneficial effect against neurological disorders caused by lead intoxication especially during development. This effect could be due to the anti-oxidant potential of aniseeds, which was related to their content of bio-actives molecules such as Flavonoids and phenolic or due to the presence of Anethole, which is structurally related to Catecholamine, Adrenaline, Noradrenaline and Dopamine. Further, more studies have to be conducted to know the compound(s) is (are) responsible for the neuro-beneficial effect of aniseed and which mechanism (s) is (are) involved.

\section{Acknowledgements}

The authors are graceful to the University of Oran 1 (Ahmed Ben Bella) (Algeria), for its financial support which allows us to carry out this study, and we thank all the team of Bio-Experimental Toxicology, Bio -Depollution and Phyto-remediation laboratory for their participation in this work and in first our technician Miss. Guenzet Akila for her help in the different techniques and manipulations. We are graceful to Mr. BEKARA Mohamed El Amin, which performed statistical analysis.

\section{Declaration of Interest}

No financial or personal conflict, were recorded between the authors of this document during the realization of this work. 


\section{Abbreviation}

P.A.E: Pimpinella anisum aqueous extract, Pb: Lead, OF: Open Filed; FST: Forced swimming test; E.O: Essential oil, ALP: Alkaline phosphatase, TBARS: Thiobarbituric assay, CAT: Catalase, LDH: Lactate dehydrogenase, 5HT: Serotonin, 5HTA1: serotoninergic receptors, $\mathbf{C a}^{2+}$ : Calcium, CRF: Corticotropin relating factor, NMDA: N-methyl-D-aspartate, ROS: Reactive oxygen species.

\section{REFERENCES}

[1] Kosalec I, Pepljnak S and Kustrak D. (2005) Antifungal activity of fluidextract and essential oil from anise fruit (Pimpinella anisum L, Apiaceae).Acta Pharm. 55(2005) 377-385.

[2] Kareydiyyeh, S.I., Usta, J., Knio, K., et al. (2003). Aniseed oilincreases glucose absorption and reduces urine output in the rat. Life Sci, 74(5): 663-73.

[3] Al Mofleh A,Alhalder A, MossaJS,et al. (2007) “Aqueous suspension of anise "Pimpinella anisum" protects rats against chemically induced gastric ulcers," World Journal of Gastroenterology, vol. 13, no. 7, pp. 1112-1118,.

[4] Gulçın I, OktayM, KıreçcıEand KufrevıogluI (2003) Screening of antioxidant and antimicrobial activities of anise (Pimpinella anisumL.) seed extracts. Food Chemistry 83 (2003) 371-382.

[5] Karimzadeh F, Hosseini M, Mangeng D, et al. (2012). Anticonvulsant and neuroprotective effects of Pimpinella anisum in rat brain. BMC Complementary and Alternative Medicine, 12:76.

[6] Xu J, Yan HC, Yang B, et al. (2009). Effects of lead exposure on hippocampal metabotropic glutamate receptor subtype 3 and 7 in developmental rats. J. Negative Results BioMed. 8(5): $1-8$.

[7] Hosseinzadeh H,Tafaghodi M, Abedzadeh S,et al. (2013)Effect of aqueous and ethanolic extracts of Pimpinella anisum L seeds on milk production in rats. Journal of Apiculture and Meridian studies (2013), http://dx.doi.org/10.1016/j.jams...10.004.

[8] Kahloula K, Slimani M, Houari D, et al. (2013). Neuro beneficial effects of Pimpinella anisum against lead exposure. International journal of green pharmacy. Department of Biology, Biochemistry Laboratory, Saida University, Saida 20000, Algeria. IJGP_178_12R8.

[9] Ait Hamadouche. N, Slimani .M and Aoues .A (2009). Biochemical Parameters Alterations Induced by Chronic Oral Administration of Lead Acetate in Albinos Rat. American Journal of Scientific Research ISSN 1450-223X Issue 4, pp $5-16$

[10] Okhawa H, OhishiN, Yagi K (1982) Assay for lipid peroxides in animal tissues by Thiobarbituric acid reaction. Anal Biochem 95: 351-358.

[11] Bergmeyer HU (1975). Catalase in methods of enzymatic analysis. Second edition, Verlag chemie, Weinhein, Germany. pp 673-684.

[12] Adonaylo, VN and Oteiza IP (1999). Lead intoxication defenses and oxidative damage in rat brain. Toxicology, 135: 77-85.

[13] Reddy GR, Basha MR, Devi CB, et al. (2003) Lead-induced effects on acetylcholinesterase activity in cerebellum and (hippocampus of developing rat. Int J Dev Neurosci 21: 347-352.

[14] Prasanthi JRP, Reddy HG, DeviBC,et al. (2005) Zinc and calcium reduce lead induced perturbations in the aminergic system of developing brain. Biometals 18(6): 615-626.

[15] Antonio MT, Corredor L, Leret ML (2003). Study of the activity of several brain enzymes likes markers of the neurotoxicity induced by prenatal exposure to lead and/ or cadmium - toxicology letters 143, 331-340.

[16] Reddy R, DeviBC,Chetty CS(2007). Developmental lead neurotoxicity: alteration in brain cholinergic system neurotoxicology $28402-407$.

[17] Leasure JL, Giddabasappa A, Chaney S, et al. ( 2008). Low-level human equivalent gestational lead exposure produces sex-specific motor and coordination abnormalities and late-onset obesity in year-old mice. Environ Health Perspect; 116:355-61.

[18] Yang Y, Ma Y, Ni L, et al (2003) Lead exposure through gestation-only caused long-term learning/memory deficits in young adult offspring. ExpNeurol 184: 489-495.

[19] Kim R, Hu H, Rotnitzky A, et al. (1995). A longitudinal study of chronic lead exposure and physical growth in Boston children. Environ Health Perspect; 103:952-7.

[20] Çabuk M, Alçiçek A, Bozkurt M, Imre N (2003). Antimicrobial properties of the essential oils isolated from aromatic plants and using possibility as alternative feed additives. II. National Animal Nutrition Congress. 18-20 September, pp: 184-187.

[21] Andallu B, Rajeshwari CU (2011). Aniseeds (Pimpinella anisum L) in Health and Disease Nuts \& Seeds in Health and Disease Prevention.

DOI:10.1016/B978-0-12-375688-6.10020-9 .Copyright2011 Elsevier Inc. All rights reserved.

[22] Azzoz HA and Raafat RA (2012). Effect of Lead Toxicity on Cytogenisity, Biochemical Constituents and Tissue Residue with Protective Role of Activated Charcoal and Casein in Male Rats. Australian Journal of Basic and Applied Sciences, 6(7): 497-509.

[23] Mansouri MT, Naghizadeh B, López-LarrubiaP,et al. (2013): Behavioral deficits induced by lead exposure are accompanied by serotonergic and cholinergic alterations in the prefrontal cortex. Neurochemistry International 62 , 232-239.

[24] Hassan A.A and Jassim HM (2010) Effect of treating lactating rats with lead acetate and its interaction with vitamin $\mathrm{E}$ or $\mathrm{C}$ on neuro behavior, development and some biochemical parameters in their pups. Iraqi Journal of Veterinary Sciences, Vol. 24, No. 1, (45-52).

[25] Anderson N, Hughes R (2008). Increased emotional reactivity in rats following exposure to caffeine during adolescence. NeurotoxicolTeratol, 30: 195-201. 
[26] Sahraei H, Ghoshooni H, Hossein S (2002). "The effects of fruit essential oil of the Pimpinella anisum on acquisition and expression of morphine induced conditioned place preference in mice,"Journal of Ethnopharmacology, vol. 80, no. 1, pp. $43-47$.

[27] EstradaCamarena. E, Fernandez Guasti A, Lopez Rubal Cava $\mathrm{C}(2006)$. Participation of the 5HT1A receptor in the antidepressant like effect of estrogens in the forced swimming test. Neuro psycho pharmacology. 31:24755

[28] De Souza Lisboa SF, Gonçalves G, Komatsu F, et al.(2005). Developmental lead exposure induces depressive-like behaviour in female rats. Drug Chem Toxicol; 28:67-77.

[29] Koch C, Reichling J, Schneele J, et al. (2008). Inhibitory effect of essential oils against herpes simplex virus type 2.Phytomedicine, 15(1-2):71-78.

[30] Waumans D, Bruneel N, Tytgat J (2003). Anise oil as para-methoxyamphetamine (PMA) precursor. Forensic SciInt, 133(1-2):159-170.

[31] Abdul-Ghani A, El-Lati SG, Sacaan AI, Suleiman MS (1987). Anticonvulsant effects of some Arab medicinal plants.Int J Crude Drug Res, 25:39-43.

[32] Pourgholami MH,Majzoob S, JavadiM, et al. (1999). The fruit essential oil of Pimpinella anisum exerts anticonvulsant effects in mice. Journal of Ethnopharmacology 66, $211-215$.

[33] Janahmadia M, Farajnia S, VatanparastJ,et al. (2008). The fruit essential oil ofPimpinella anisum. (Umblliferae) induces neuronal hyperexcitability in snail partly through attenuation of after-hyperpolarization. Journal of Ethnopharmacology $120 ; 360-365$.

[34] Allouche L, Hamadouche M, Touabti A, et al.(2011). Effect of Long-term Exposure to Low or Moderate Lead Concentrations on Growth, Lipid Profile and Liver Function in Albino Rats. Advances in Biological Research 5 (6): 339-347.

[35] Mehana, E.E., MekiMAand Fazili, KM (2010). Ameliorated effects of green tea extract on lead induced liver toxicity in rats. Exp. Toxicol. Pathol. 645(4): 291-5.

[36] Khan, M.S.H., Mostafa MS, Hossain MA,et al. (2008). Effect of garlic and vita-min B-complex in lead acetate induced toxicities in mice. Bang. J. Vet. Med., 6(2): 203-210.

[37] Ibrahim NM, Eweis EA, El-Beltagi HB,et al. (2012). Effect of lead acetate toxicity on experimental male albino rat. Asian Pac J Trop Biomed; 2(1): 41-46.
[38] Moussa SA and Bashandy SA (2008). Biophysical and Biochemical Changes in the Blood Of Rats Exposed to Lead Toxicity. ROMANIAN J. BIOPHYS., Vol. 18, No. 2, P. 123-133, BUCHAREST.

[39] Fonta C, Negyessy L, Renaud L, et al. (2005) postnatal development of alkaline phosphatase activity correlates with the maturation ofneurotransmission in the cerebral cortex. JCompNeurol 486(2):179-196.

[40] Rajeshwari CU, Abirami M, Andallu B (2011). In vitro and in vivo antioxidant potential of aniseed (Pimpinella anisum L.). Asian J ExpBiol Sci. 2(1): 80- 89.

[41] Edrees G, Amer M, El-shamyK,et al. (2013). Mammalian Neuro Endocrinological Changes and Oxidative Stress during Chronic Lead Intoxication. J Bioanal Biomed, 5:1

[42] Ahamed M, Siddiqui MKJ (2007): Low level lead exposure and oxidative stress: Current opinions. ClinicaChimicaActa $38357-64$.

[43] Garcia' MT, Masso'-Gonzalez EL (2008) . Toxic effects of perinatal lead exposure on the brain of rats: Involvement of oxidative stress and the beneficial role of antioxidants. Food and Chemical Toxicology $46 ; 2089-2095$.

[44] Alghazal MA, LenártovaV, Holovska K, et al. (2008). Activities of Antioxidant and Detoxifying Enzymes in Rats after Lead Exposure. ACTA VET. BRNO, 77: 347-354.

[45] Shobha RI, Rajeshwari CU, Andallu B (2013). Anti-Peroxidative and Anti Diabetic Activities of Aniseeds (Pimpinella anisum 1) and Identification of Bioactive Compounds. AJPCT [1] [5] 516-527.

[46] Sidhu P and Nehru B (2004). Lead intoxication: histological and oxidative damage in rat cerebrum and cerebellum journal of trace element in experimental medicine. 17:45-53 (2004).

[47] Aebi, H. (1974) Catalase. In: Bergmeyer, H. V., ed. Methods of enzymatic analysis. Basel: Verlag Chemie; 673-684.

[48] Yildirim A., Mavi, A., Kara, A A (2001). Determination of antioxidant and antimicrobial activities of Rumaxscrispus L. extracts. Journal of Agricultural and Food Chemistry, 49, 4083-4089.

[49] Diplock A. T. (1997). Will the 'good fairies' please proves to us that vitamin $\mathrm{E}$ lessens human degenerative of disease? Free Radical Research, 27, 511-532. 